Volume 8, No.3, May - June 2019

International Journal of Advanced Trends in Computer Science and Engineering

Available Online at http://www.warse.org/IJATCSE/static/pdf/file/ijatcse61832019.pdf

https://doi.org/10.30534/ijatcse/2019/61832019

\title{
Cloud Connectivity for Embedded Systems
}

\author{
K Jyothi ${ }^{1}$, R Karthik ${ }^{2}$ \\ ${ }^{1}$ Department of Electronics and Communication Engineering, MLR Institute of Technology, Hyderabad, India \\ jyothi.tan@gmail.com \\ ${ }^{2}$ Department of Electronics and Communication Engineering, MLR Institute of Technology, Hyderabad, India :
}

Karthik.r@mlrinstitutions.ac.in

\begin{abstract}
Presenting an embedded system that acts as a regulator for electronics is not innovative. Nowadays these sorts of frameworks are surrounding us and are utilized for a huge number of obstinacies. Equally, distributed computing is a moderately new method for processing all in all. This statement venture investigates these two advancements (Cloud and Inserted frameworks) with a specific end goal to make a support between these two uncontrollably unique stages. Such an extension should empower better approaches for uncovering highlights and doing upkeep on inserted gadgets. This could spare organizations not just time and cash while managing support garages for implanted frameworks, however this ought to likewise maintain a strategic distance from the expected to have this upkeep programming on devoted servers - rather these undertakings could utilize cloud assets just when required. This proposal investigates such a scaffold and exhibits procedures appropriate for joining these two figuring models together.
\end{abstract}

Key words: Cloud connectivity; Embedded Systems; Framework.

\section{INTRODUCTION}

Cloud Administrations has all through the latest couple of decades transform into an important stage for associations due to its ability to diminish costs and in light of the way that this perspective prompts a directed IT establishment that can be used to viably plan and estimation organizations. The cloud includes both gear and programming gave by a server ranch to which a customer pays only for the benefits that they use. Disseminated processing mishandle Cases or virtual machines (VM/Example s) running on bundles of PCs. These PCs can either be adjacent or at an encouraging provider. The last course of action engages the customer to change the measure of the virtual machines on the fly as in light of the segment of the request. This makes versatile condition that can be used to talk assorted circumstances and times of an application's utilization (association, upkeep, and support). The customers of this versatility arrangement from first class figuring (Elite Registering) (for example a customer can rent no less than 100 $\mathrm{VM} /$ Occasion $\mathrm{s}$ to do planning for a period of two or three hours) to dynamically scale with the help of game plan and the amounts of PCs that are used to channel and process an association's said endorsement unpretentious components [12].

While asking about scattered preparing the coordinating firm McKinsey discovered 20 ramifications of the idea. Along these lines what is seen as spread handling can contrast between various suppliers and affiliations. The Unified Conditions of National Organization of Principles and Innovation (NIST) of America delineates the scattered enrolling as a model for an on- request pool of dealt with taking care of assets which can be passed on quickly and with superfluous participation.

Implanted frameworks have been conveyed in different situations to go about as controllers. Such frameworks are very predominant today. These frameworks have extraordinary, outlines, capacities, and utilization. Interfacing these frameworks to the Internet has been done to a fluctuating degree, yet much of the time these frameworks have just been associated with inside systems. Empowering these frameworks to safely work when utilized as Internet empowered gadgets requires thought of the inserted framework's regularly constrained abilities. Be that as it may, the execution of inserted frameworks has expanded subsequently this before paper was distributed in 2005. Now, the expansion of installed frameworks to help protected reconstructing had been inspected by Mussie Testate in his current Master's proposition. Today an expanding division of these implanted frameworks are being associated with the Internet and shape an Internet of things. Present day machines remain composed and made with updated inserted gadgets with the purpose that the subsequent apparatus will be Internet empowered. Edifice this ability amid improvement gives the originator a chance to report worries that are hard to discourse while growth of the Internet availability to as of now sent inserted frameworks.

Investigating what is incorporated into distributed computing by looking at accessible innovations for organization is critical to have the capacity to get a photo of what the market brings to the table. All the more vitally is the manner by which such a sending should be possible and what the advantages are. How advancements, for example, System parts, stockpiling segments, databases, stack balancers, and figuring situations have been adjusted to a cloud domain and what disadvantages and new highlights are accessible in this condition are of intrigue and how an answer can abuse these highlights in a genuine situation. A wide range of cloud suppliers and significantly three and their items have been introduced 
keeping in mind the end goal to make an outline of the present offerings.

This theory introduces the idea and arrangement of cloud availability for implanted frameworks following this proposition portrays a model of how such an answer could be recognized and utilized. The proposition evaluates current cloud providers to the extent the requirements of the model.

A center product arrangement drawing qualities since the administrations presented by cloud specialist organizations for sending at a seller is proposed. This inside item acts stateless to give correspondence and partner of value Dynamic between two social affairs with different limits. This approach makes an adaptable shared conviction for end-customer clients and reduces the heaviness of having the embedded structures themselves process and pass on information to the clients. The plan furthermore gives and impression of the introduced structures moreover ensuring the correspondence with the systems by it simply being enabled for considerable focus item organizations [4-5].

\section{CLOUD COMPUTING}

Cloud computing enables the users to store files and various applications on remote servers and retrieve all the data later through the Internet. It is the result of utility computing, grid computing and automatic computing. The services provided by the cloud computing can be both public and private. While public services are rendered for a fee, private services are provided on a network to specific clients.

\section{A. Representation of Cloud Services}

Cloud computing may be a disruptive change to the way the IT services of an enterprise are delivered. This paper at the end describes the cloud computing reference architecture that builds the private clouds for clients and also the private clouds which house applications and support our public cloud service offerings.

A cloud is called a private cloud if it is utilized by a solitary organization. A private cloud can be either altogether facilitated or worked by the organization itself or can be situated at a co-facilitating office. Explanations behind considering and picking these methodologies for these private clouds are simply the control and security of the stage itself.

Illustration, we have significantly AMAZON WEB SERVICES, Azure, Rackspace and Soft layer who gives in view of individual organization or association needs

Public clouds vary from private clouds. In a public cloud an open cloud is situated on a common foundation and imparts assets and equipment to various clients. These assets might be situated in similar server farm and might be worked by an outsider. Here the security parts of utilizing a cloud turn out to be all the more appearing as different elements are sharing a typical foundation. Securing the administrations gave so as to restrain the risk of data spillage ought to be viewed as a need. The ways this data can spill are portrayed in Victor Delgado's Master's postulation.
The blend of both a private and open cloud is called a hybrid cloud. An organization may run a separate cloud without anyone else's equipment in-house, while using as vital assets such a registering force and capacity assets in an open cloud worked by an outsider. The administration models gave by a cloud seller are displayed and are depicted as takes after: Example, we have significantly AMAZON WEB SERVICES, Azure, Rackspace and Soft layer who gives in view of individual organization or association needs.

There are four essential distributed computing organization models which are accessible to benefit shopper as appeared in Figure 1.

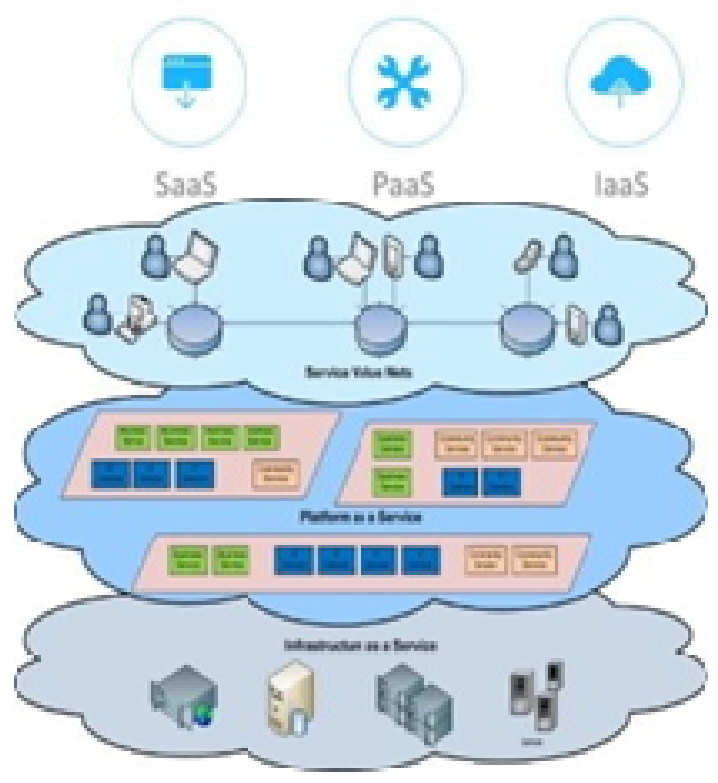

Figure 1: Types of cloud service Models

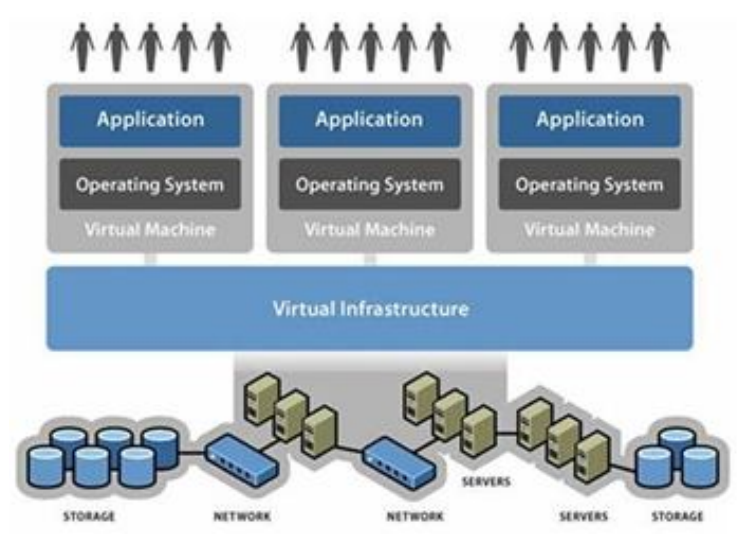

Figure 2: Virtualization of mechanism 
K Jyothi et al., International Journal of Advanced Trends in Computer Science and Engineering, 8(3), May - June 2019,731 - 733

\section{VIRTUALIZATION FOR CLOUD COMPUTING}

Virtualization in cloud computing uses a specialized software and creates a virtual or software-created version of a computing resource instead of the actual version of the same resource. Virtualization has several benefits which include: security and flexibility. Figure 2 shows the schematic of Virtualization of mechanism.

\section{A. Security}

Security is one of the important concerns in the cloud computing. The security is provided by the firewalls that prevent unauthorized access and keep the data confidential [69].

\section{B. Flexibility}

Locating the required data and transferring that to the allotted authorities is easy because of Virtualization. With the minimum possible fee the unlimited data can be transferred to a long distance.

\section{Advantages}

$>$ Cost savings
$>$ More resource Utilization
$>$ Security
$>$ Flexibility
$>$ Increased collaboration
$>$ Automatic software updates
$>$ Faster deployment

\section{Disadvantages}

$>$ Requires a constant internet connection

$>$ Requires high speed internet connection

$>$ Data transfer costs

$>$ Vendor lock-in

\section{CONCLUSION}

Distributed computing has several advantages and deals with the most sudden, impermanent tops in application request on cloud foundations. Virtualization innovation provides a reat help in accomplishing point of distributed computing such as higher asset usage, flexibility, lessening IT cost or capital use to deal with transitory loads. Furthermore specialized help is needed for versatile adaptability to serve by vertical scaling approach that is currently restricted to just flat scaling.

\section{REFERENCES}

[1] Michael Armbrust, Armando Fox, Rean Girth, Anthony D. Joseph, Randy Katz, Andy Kaminski, Gunho Lee, David Patterson, Ariel Rabkin, Ion Stoica, and Matei Zaharia, "A view of cloud computing", 2002.

[2] Sun Microsystems, "Introduction to cloud computing", White paper. 2009.

[3] McKinsey \& Company, "Clearing the air on cloud computing", Technical report, 2008.

$\begin{array}{lllr}\text { [4] } & \text { Meter Mell and } & \text { Tim } & \text { Grance, } \\ \text { The } & \text { NIST }\end{array}$ The NIST Denition tions/ of nistpubs/800145/SP800- 145.pdf,2009, National Institute of Standards and Technology, Information Technology Laboratory.

[5] Srivaths Ravi, Anand Raghunathan, Paul Kocher, and Sunil Hattangady.Security in embedded systems: Design challenges. ACM Trans. Embed.Comput. Syst., 3(3):461-491, August 2004. https://doi.org/10.1145/1015047.1015049

[6] Kevin Lee, David Murray, Danny Hughes, and Wouter Joosen., "Extending sensor networks into the cloud using Amazon web services", In NESEA'10,2010 https://doi.org/10.1109/NESEA.2010.5678063

[7] Javier Diaz, Gregor von Laszewski, Fugang Wang, and Georey Fox, "Abstract image management and universal image registration for cloud and hpc infrastructures", In Rong Chang, editor, IEEE CLOUD, pages 463470.IEEE, 2012

https://doi.org/10.1109/CLOUD.2012.94

B.Manoj, K.V.K.Sasikanth, M.V.Subbarao and V Jyothi Prakash, "Analysis of Data Science with the use of Big Data", Vol. 7, No. 6, International Journal of Advanced Trends in Computer Science and Engineering, 2018.

[9] S.V.R.K.Rao, M.Saritha Devi, A.R.Kishore and Praveen Kumar, "Wireless sensor Network based Industrial Automation using Internet of Things (IoT)", Vol. 7, No. 6, International Journal of Advanced Trends in Computer Science and Engineering, 2018.

https://doi.org/10.30534/ijatcse/2018/01762018 